to suicide, it was thought by myself and others, that his obstinate refusal of food was associated with ideas of self-destruction. $\mathrm{He}$ died, and at the post-mortem examination a stricture in the pylorus was discovered. These illustrations, and they could easily be extended, will prove the importance of paying minute attention to particular delusions, with the view of ascertaining whether they have not a particular and actual physical origin.

The prognosis in cases of insanity will mainly depend upon the duration of the attack, its character and origin, and the diathesis of the patient. The prognosis is generally unfavourable if the disease is hereditary - if the symptoms are similar in character to those exhibited by other members of the family when insane. Insanity, accompanied by acute excitement, is, cceteris paribus, more easy of cure than when it has been of slow and gradual growth, and is marked by great mental depression. The prognosis is favourable in cases of puerperal mania; it is unfavourable when there exists a want of symmetry between the two sides of the head, with small anterior, and large posterior cerebral development. Any great inequality in the cranial conformation would be a suspicious indication. The existence of any malformation in the development of the chest is also an unfavourable sign, and would induce us to give a guarded prognosis. Dr. Darwin says, when a person becomes insane, who has a small family of children to absorb his attention, his prospect of recovery is but small, as it establishes that the maniacal hallucination is more powerful than those ideas which usually interest us most. The prognosis is unfavourable when patients are under the morbid delusion that they are poisoned, and are constantly suffering internally from peculiar sensations. Religious delusions are more difficult to eradicate than other morbid impressions. The age of the patient will materially guide us in forming a correct prognosis. Hippocrates says the insane are not curable after the fortieth year; Esquirol maintains the greater portion recover between the ages of twenty and thirty; Haslam between the ages of ten and twenty. As a principle, we may conclude that the probability of recovery in any given case is in proportion to the early age, physical condition, and duration of the attack. When a patient has youth and a good constitution to aid him, and is advantageously placed, having at command remedial measures, and is excluded from all irritating circumstances, the prognosis may be favourable. I have seen patients after the advanced age of sixty and seventy recover; and cases of cure are upon record where insanity has existed for ten, fifteen, and twenty years. In forming our prognosis, it is important to ascertain the educational training of the patient. Has be been in the habit of exercising great self-control? Has his mind been well disciplined? Has he kept in abeyance the passions, or have the emotions and impulses of his nature obtained the mastery over him? He who has been taught to practise self-denial and self-control in early life is, cceteris paribus, in a more favourable position for recovery than he who has permitted himself to be the willing and obedient slave of every passion and caprice. Insanity, accompanied with criminal propensities, is said to be incarable, because, as Ideler urges, such patients "cannot bear the torments of their consciences, and relapse into the stupefaction of insanity to flee from the consciousness of their gnilt."* The prognosis is unfarourable when the insanity is complicated with organic disease of the heart and lungs, with deafness, and paralysis in any of its forms. * Lesions of the motor power are very unfarourable indications. Great impairment of mind, accompanied with delusions of an exalted character, and associated with paralysis, is generally incurable. Esquirol says, epilepsy, if associated with insanity, places the patient $b \rightarrow y$ ond all prospect of cure. I should be loath to adopt this sweeping condemnation. I have seen cases of epilepsy, combined with mental derangement, recover; although, I admit, they constitute a difficult class of case to manage.

(To be concluded.)

* "No discase of the imagination is so difficult of cure as that which is complicated with guilt; fancy and con-cience then are interchangeably upon us, so often shift their places, that the illusions of the one are not distinguished from the dictates of the other. If fancy presents images not moral or religious, the mind drives them away when they give it pain ; but when melancholic notions take the form of duty, they lay hold of the faculties without opposition, because we are afraid to exclude or banish them : for this reason, the superstitious are always melancholy, and the melancholy always superstitions." -Dr. JoInson. Rasselas.

"Deafness is not of itself a symptom of insanity, but it is often a concomitant, and their combination forms incurable insanity. The reason probably is, that the same cause which destroys the hearing, or affects the auditory nerve, extends also to the brain itself."-DR, BRIGHAM.

The Yellow Fever.-This disease has considerably abated at Martinica, but has just broken out at Basse Terre (Guadeloupe), and several cases have occurred among the garrison. The epidemic has likewise appeared in St. Thomas and St.Lonis. The small-pox has much diminished at Jamaica.

\section{ON THE TREATMENT OF DIARRHCEA BY SULPHURIC ACID.}

BY C. M. MILLER, M.D., Stoke-Newington.

$\mathrm{I}_{N}$ The Lanout of August 30, 1851, sulphuric acid was recommended in the treatment of diarrhoa. We are informed by the public journals, that the Asiatic cholera is making rapid strides towards our coast, and that two members of the Board of Health are watching its progress. I think, then, I shall be pardoned for drawing the attention of the medical public once more to this remedy; and in order that $I$ may not be supposed to recommend what I have not myself had experience of, $I$ have liere subjoined an abstract of twentseven cases of English cholera and diarrhoea, in which $I$ have tried this plan during the last month, with one uniform result. I commenced it in the middle of Angust, and now leave the cases to speak for themselves."

1. August 9th.-Mrs. W-_'s infant, aged four months. When first called to this case, I found the child perfectly exhausted by diarrhœa and vomiting. She had been already ill three or four days; sunken eyes, and apparently very near death. The bowels were now constantly open, and there was continued sickuess. I tried a variety of means until the 16 th; I then commenced the dilute sulphuric acid. On the 17 th the diarrhœa was much better; on the 20th the child was well.

2. Mrs. B-_'s infant, aged twelve weeks; was attacked August 13th with diarrhœa. Similar means were used as in case 1, without much good effect for a few days, when the acid mixture was tried, and the child was relieved by the first dose.

3. August 22nd. Mrs. T-_'s child, aged ten months, had been suffering from diarrhoa for the last few days. Was ordered the acid mixture. The first two doses were returned, but after the third dose the child got better. This child took sixteen doses before entire relief was obtained.

4. Mrs. S-, a patient in the Invalid Home, Islington, aged thirty-six, has been suffering from diarrhœa for a week. The third dose of the mixture checked the diarrhœa, but on leaving the medicine off the relaxation returned; she continued it for two days, and was quite well. This patient was in the Home for spinal irritation.

5. Anne $\mathrm{H}-$, aged twenty-six; in the Home for pelvic abscess; has suffered from diarrhoea for three or four days. Took two doses of the mixture, and it was stopped.

6. D-, aged sixty, a nurse in the Home; has been suffering from diarrhœa for a fortnight. One dose of the mixture stopped it.

7. Mr. S-, aged between fifty and sixty, a gardener; had been ill for twenty-four hours. Nine doses cured him.

8. Miss S- - aged thirty-eight, was first attacked August 31st. Commenced the mixture; was better Sept.1st, and well Sept. 2nd.

9. Mr. F__ gardener, aged thirty-eight, was attacked August 31 st, with violent purging and sickness; tongue very much furred; applied to me Sept. 2nd, came again Sept. 3rd, and said he was quite well. The first dose stopped it.

10. V_-, an oinnibus conductor, aged thirty-two, was very much purged, and felt sick; two doses relieved him.

11. Mrs. B-, between fifty and sixty years of age, was attacked in the night of the 2 nd of Sept. with violent purging and sickness. Had the mixture early on the $3 \mathrm{rd}$; was relieved by two doses, but as she is naturally of a relaxed habit of body, she continued the mixture for a few days.

12. Mr. L—'s child, aged four months, while under the influence of vaccine, was attacked with diarrhoa; was relieved by the mixture, but not to the satisfaction of the father, who is a chemist, and who substituted an opiate mixture which I had ordered on a former occasion. This child was, however, doing very well under the acid.

13. Mrs. B-C's child, two years and a half old; the bowels had been relaxed for three weeks; one bottle of the mixture cured the child.

14. Mrs. C-_'s child, aged thirteen months, has been relaxed since yesterday, Sept. 4 th, the bowels acting every ten minutes; the child took two bottles of the mixture, and was well.

15. Mrs. F-, aged thirty-five, and child, aged nine months, both suffering from diarrhœa, cured with one bottle each.

$$
\begin{aligned}
\text { * The following is the prescription for the mixture :- } \\
\text { B. A Acid sulph. dilut., } 3^{\mathrm{ij} .} \\
\text { Tinct. card. comp., } 3 \mathrm{j} \text {. } \\
\text { Aqua distill. } 3 \text { rss. }
\end{aligned}
$$

F.M. Capiat cochl. duo statim et repet. post singul. liquid. sedes vel vomit. et omnibus quat. horis. 


\section{MR. HAYWARD ON THE TREATMENT OF TYPHOID FEVER BY DISULPHATE OF QUINA.}

16. $\mathrm{Mr} . \mathrm{B}-$ aged sixty-five, diarrhcea and sickness with cramps; much better after the first bottle; well after the second.

17. Mrs. A-_'s child, aged one year and a half, had been relaxed for many days, and was falling away very fast; much relieved after one bottle.

18. Mrs. $\mathrm{O}-$, aged twenty-five, diarrhœa; felt quite comfortable after the first dose. I have frequently attended this young person for colic.

19. Mrs. M 's child, aged one year and a half. Diarrhcea, mixed with much blood; and, according to the sister's account, who brought the child to me, was acted upon every ten minutes. After one bottle of mixture was relieved, but three or four times a day. No other treatment was used, and the child was quite well.

20. Mrs. C-'s child, aged nine months, was attacked, September 12 th, with violent purging and sickness; this continued, and she was first seen by me on the 15 th, at nine o'clock in the evening. I found her with sunken eyes, contracted features, blueness about the mouth, partially insensible, and cold ; in fact, apparently dying. She took twelve doses of the mixture and the purging ceased, but the exhaustion was so great that I feared for some days that $I$ should lose her; she, however, is recovering, having taken nothing but ammonia and nourishment after the purging had ceased.

21. Mr. J. L_-, aged twenty-one, Sept. 14 th, was first attacked with pain, then constant diarrhoea. Six doses relieved him entirely.

22. Sept. 20th.-Mrs. F-_'s danghter, aged thirty; has been ill for some days with violent purging, everything she takes passing through her as she takes it. The motions were at first black, then and now, light and knotty. She took three doses and was well.

23. Sept. 14th.-Mrs. W-_'s child, aged seven months, was violently purged and sick; the second dose relieved her, and, to use her mother's expression, the evacuation from the bowels was like a child three years old.

24. Sept. 20th.-Mrs. M-_'s child, aged eight months; has been suffering from diarrhoa for the last six days, and has now a motion every five minutes. After one dose of the mixture the purging ceased, and now, twelve hours after commencing the mixture, he has had but one action of the bowels, and that is more consistent.

25. Sept. 21st.-Mrs. B-_'s child, aged four years; diarrhcea commenced at two o'clock this morning; has had very much action on the bowels like jalap; first dose checked it, and he has only had three actions since he commenced.

26. Sept. 22:-Mrs. P__, aged about twenty-eight years; has had diarrhoea for three weeks, until she has become quite blanched; has had four actions since six o'clock this morning, and it is now only nine; pulse feeble; papills of tongue much elongated; pain in the loins and bowels; feet and legs swelling; she quite staggered from debility when she left my house; she says her natural colour is florid.- Sept. 23: She took three doses of the mixture, and the diarrhoa entirely ceased; her colour is already returning, and she says she has not been so well for these two months.

27. August 24.-Mrs. C-_'s servant, aged thirty-two; was attacked with purging, sickness, and pain, with cramps. She took twelve doses of the mixture, and was well. The first two doses relieved her very much.

Here, then, are twenty-seven cases, not picked from a number of others, but taken fairly as they have occurred, one after the other, in my practice, during the last month-of all ages, from the infant upwards. I think, Sir, it was you who said, some few years past, that if we wished to arrive at the value of any remedy or plan of treatment, we must apply to it the numerical test. I think the above plan will fully bear that test. Of these cases, many were of a very severe character, and wanted but little to make them come under the denomination of Asiatic cholera: witness Cases 1, 2, 9, 17, 19 , 20, and 26. We all know the intractability of infantile diarrloea-and several of the above were such-but they yielded equally with those of more mature years. Theorizing is not of much use at present, although I have a theory regarding its mode of action. I only now ask the profession to try this remedy; and I earnestly entreat the Board of Health, before sending forth a list of means such as were formerly published, to give this remedy a trial. I have so much confidence in it, that, should we be visited by that awful scourge, the Asiatic cholera, I should instantly resort to it.

A few more words before quitting this sulject. During the last visitation of cholera, our district was declared to be very nearly the healthiest in the neighbourhood of London; but who shall say that this will be the case on its next ap. proach? With a Stygian stream meandering amongst us, which, because it is not sufficiently polluting, has just been made to receive, through a common sewer, the drainage of an entirely new neighbourhood-over-loaded drains and cesspools at our very doors, and without the means of removing their contents, except through our houses-can we expect to get off so easily? For fourteen years have the inlabitants of the district been paying at intervals a sewer's-rate, and to what advantage? A memorial was presented, a few weeks past, to the Commissioners of Sewers, signed by the medical men, and very many of the influential inhalitants of the neighbourhood, complaining of the drainage; and what has been the result? Little or nothing. Will it be believed, that in the centre of densely populated neighbourhood, within two miles of Shoreditch Church, there runs a road, which in wet weather is in such a state that it becomes impossible to cross it without walking through a small pond. If the cholera does come, let the Commissioners of Sewers look to it; for if we suffer more this time than we did the last, they certainly must take a very large share of the blame.

Stoke Newington-road, Sept. 1852.

P.S.-Since writing the above, other cases equally successful from the saine remedy have come under my notice; but these I shall reserve for a future occasion.

\section{REMARKS ON THE TREATMENT OF TYPHOID} FEVER BY DISULPHATE OF QUINA.

BY J. W. HAYWARD, Esq., Liverpool.

IN a practice, private and parcchial, of which I have had charge for some time, at the south end of this town, I made particular observations on eighty successive cases of fever of the typhoid type; and I found the first symptom, in twenty of them, was diarrhœa; in twelve, diarrhœa and vomiting; in seven, vomiting alone; the rest began with pain in the head. All had pain in the head afterwards; sixty-six describing it as "lightness," fourteen as " heaviness." All had tenderness of abdomen-nine to a great extent. Seventy-one complained of soreness of the flesh over the whole body-some to such an extent that their impression was that they had rheumatism. Seventeen had considerable inflammation of the sub-maxillary glands. Seventy-three had delirium, twenty-one of which were very severe. In all, the tongue became very dry, brown, hard, and cracked; the first crack was generally a deep, longitudinal one down the centre of the tongue, (even whilst it was clammy and velvety in appearance, and of a millk-and-water colour, extending from the base to nearly the apex; then many transverse and oblique ones. In twenty four, the skin became rough and brown, with petechia observable. In all, the thirst was intense; and the other symptoms of fever were not less evident; therefore suffice it to say, they were wellmarked cases of fever of the typheid character.

In twenty-seven the treatment was commenced in the "first stage;" in fifty-three, in the "second stage." Three were fatal. All the rest recovered more or less quickly.

The principal treatment in all except one was the use of disulphate of quina, - so much recommended by Dr. Dundas, of this town, - of course modified according to the predominating symptoms. Thus, if I found the pulse quick, weak, and thready; the tongue cracked, brown, and dry, (rough or smooth;) great thirst and delixium; no appetite; tenderness of abdomen; soreness of flesh, "\&c., I put the patient upon disulphate of quina, in solution, at once; four or five grains every two hours. If great restlessness, and no sleep, I added three or four minims of tincture of opium to each dose. If general sinking of vital powers, some wine or brandy, with beef-tea. If the solution of quina were vomited, it was given in an equal quantity of wine, or wine-and-water. If the patient continued sinking, I increased the quantity of quina, but never had occasion to extend beyond seven grains per dose. When ringing in the ears occurred, the quantity was decreased, but still kept up till there was a good appetite. If the delirium was intense, the pain in the head described as heavy, (which were always strong subjects, whose bowels were confined,) with strong pulse, a dose of chloride of mercury, and sometimes a blister to the nape of the neck. If tenderness of abdomen was great, a few leeches, or sinapism. If vomiting, a sinapism over the stomach. If diarrhœa, a little calomel and opium, or diacetate of lead and opium; though this symptom sometimes required nothing more than the tincture of opium given with the quinine.

In seventy-nine cases, marked improvement was observable 